\title{
Notes from the Field in Kigoma, Tanzania
}

\begin{abstract}
In these short notes the authors provide some insight to their' visit to displaced persons camps in Kigoma, Tanzania. This trip marks the fourth set of camps examined in the PostEmergency Phase Indicators Project, a joint collaboration between the Johns Hopkins Center for Refugee and Disaster Studies, and the International Emergency and Refugee Health Branch at the Centers for Disease Control.
\end{abstract}

\section{Resume}

Dans ces breves notes, les auteurs fournissent un apen;u de leur visite au camps pour personnes deplacees de Kigoma, en Tanzanie. Ce voyage marque la conclusion de la quatrieme serie de visites de camps de refugies examines dans Ie cadre du Projet sur les Indicateurs d'Etapes en Situation PostUrgente (Post-Emergency Phase Indicators Project), une collaboration conjointe du Centre John Hopkins pour les Etudes sur les Refugies etles Desastres, etla Section pour la Sante des Refugies et l'Urgence Internationale, du Centre pour Ie Contr6le Epidemique.

This Tanzanian trip marks the fourth set of camps examined in the Post-Emergency Phase Indicators Project, a joint collaboration between the Johns Hopkins Center for Refugee and Disaster Studies, and the International Emergency and Refugee Health Branch at the

Paul Spiegel MD, MPH, Senior Associate in the Department ofInternational Health at Johns Hopkins School of Hygiene and Public Health and the Center for Refugee and Disaster Research. Mani Sheik, MPH, Research Scientist in the Department of International Health at Johns Hopkins School of Hygiene and Public Health and the Center for Refugee and Disaster Research.

\section{Paul B. Spiegel and Mani Sheik}

Centers for Disease Control. So far, we have visited 29 refugee and internally displaced persons camps in the postemergency phase in Azerbaijan, Thailand and Uganda. An additional visit to six refugee camps during this visit to Tanzania will make a total of thirty-five camps so far. Further visits are planned for Nepal, Ethiopia, and Sudan. In the end, we hope to have studied over 50 different displaced persons (DP) camps in the post-emergency (ER) phase.

The Indicators project, which began one and a half years ago, is funded by the Center of Excellence in Disaster Management, based in Hawaii. It has evolved over time and now consists of the following three main objectives:

1.To analyse existing health information systems (HIS) in displaced persons (DP) camps in the post emergency phase, and the consequent pro-ision of a confidential report to the non-governmental organization (NGO) managing the HIS.

a) Analysis of HIS allows us to determine the quality of the data we will be actively collecting in the third objective.

b) Systematic analysis of the HIS in each camp, using a standardized HIS evaluation form, will allow us to develop a forthcoming manual for implementing and evaluating surveillance systems in DP camps.

2.To provide training in the ca"mps to health workers at all levels on the importance of HIS; why data should be collected and how it can be used directly in the field to make programmatic changes in order to improve the health of the population which they are serving.

3.To collect three months retrospective data from each camp on programmatic indicators (ie water and sanitation, health personnel, etc ... ), and outcome indicators (ie mortality and morbidity) using a standardised data collection form. Programmatic indicators, based on sta tistically modelled data, will be developed, which may guide NGOs programmatic decisions when working in DP camps in the postemergency phase.

Nearly all of the literature and guidelines currently in use refer to the emergency phase of a DP camp 1. The emergency phase is generally defined as $>1$ deathj10,000j day 2. Despite the large increase in mortality during this period, the emergency phase generally constitutes only a small component of the lifecycle of a DP camp. By far, the longest component is thepost-ER phase, where the mortality rate is relatively stable. Despite this stability, morbidity and its consequent decrease in the quality of life within the DP population remains a significant problem.

From preliminary descriptive analysis of the data we have collected so far, it appears that the mortality and morbidity patterns of displaced populations change in numerous different ways during the transition to the postER phase from the emergency phase. In particular, chronic non-infectious diseases, such as respiratory disease, heart disease, chronic malnutrition, and arthritis, constitute a higher proportion (proportionate mortality and morbidity) of disease burden compared to the acute infectious diseases, which gradually come under control during the emergency phase. As well, certain diseases, such as sexuallybased gender violence, reproductive health issues, and psychosocial illness, while perhaps not actually rising, are more easily recognised and addressed during the postER phase. Lastly, the demo-graphics of disease mortality and morbidity seem to shift as the phases of the DP camps evolve. In particular, the proportion (age-specific proportionate mortality) of elderly dying as compared to children under five years of age, appears to increase.

Refuge, Vol. 18, No.4 (November1999) 
It has been our impression during our visits to these camps that many UN agencies and NGOs do not yet fully appreciate the changes in disease profiles as the phases of the DP camp evolve. Indeed, for the most part, these trends have not yet been elucidated in the literature. For instance, many camps are still measuring acute malnutrition (wasting, which is height/weight) in the under 5 population while not examining for chronic malnutrition (stunting, which is height/age). Some NGOs still utilise indicators recommended for the emergency phase, despite the existence of the camp for 5-10 years. First, recommended indicators for the emergency phase are MINIMUM standards only. Thus 15-20 L/person/day of water is the minimum amount recommended during the emergency phase ${ }^{3}$. Second, in long term DP camp situations, some NGOs still have the mistaken belief that they are doing their job properly if they provide only $20 \mathrm{~L} /$ person/day of water. We have preliminary noted similar trends with respect to living space/person, the number of cases seen per health care worker in the clinic/day, and other process indicators. Furthermore, we have noted that disease surveillance systems do not always evolve with the development of a camp. If HIS' do not detect changes in disease incidence (both by noting a change in magnitude, as well as having the flexibility to adapt the system by adding or removing disease categories, as needed), then the above-mentioned changes in disease profiles may not be obseryed and the subsequent programmatic changes cannot be implemented to address them.

In summary, most of the currentPublic Health guidelines and recommendations for DP camps refer only to the emergency phase. The post-ER phase is by far the longest phase in the lifecycle of a DP camp, and it has been the least studied. Preliminary analysis from the Post-Emergency Phase Indicators Project indicates that the disease morbidity and mortality may be markedly different in the post-ER phase. In particular, chronic as opposed to acute diseases, and non-infectious as opposed to infectious diseases seem to represent a higher proportion of the disease burden than in the emergency phase. The agespecific mortality appears to shift upwards during the post-ER phase. Within the next year, comprehensive analysis of all of the data collected for the Indicators Project will hopefully lead to specific program indicators for DP camps in the post-ER phase, ultimately making the programs NGOs implement more effective and thus reducing disease mortality and morbidity while improving the quality of life.

\section{Notes}

1. The literature and guidelines in use include: Centers for Disease Control and Prevention. (1992) Famine-affected, refugee, and displaced populations: recommendations for publichealth issues. MMWR 41(RR-13); p.176.

Toole, M.J., Waldman, RJ. (1990) Prevention of Excess Mortality in Refugee and Displaced Populations in Developing Countries. JAMA 263; p.3296-3302.

Toole, M.J., Waldman, R.J. (1993) Refugees and displaced persons: war, hunger and public health. JAMA 270(5); p.600-05.

Sphere Project. Humanitarian Charter and Minimum Standards in Disaster Response. Geneva, 1998.

2. Centers for Disease Control and Prevention. (1992) Famine-affected, refugee, and displaced populations: recommendations for public health issues. MMWR 41(RR-13); p.1-76.

3. Sphere Project. Humanitarian Charter and Minimum Standards in Disaster Response. Geneva, 1998. व

\title{
Refuge
}

\section{Canada's Periodical on Refugees}

\author{
Published six times a year by the Centre for Refugee Studies, \\ York University, Toronto.
}

Available from:

Centre for Refugee Studies, York University

Suite 333, York Lanes, 4700 Keele St.

Toronto ON M3J 1 P3 